\title{
Environmental Cinnamon Extracts Effect on Electrodeposition of Copper in an Acidic Bath
}

\author{
K. Dahmani ${ }^{a}$, M. Galai ${ }^{a}$, A. Elhasnaoui ${ }^{c}$, B. Temmar ${ }^{b}$, \\ A. El Hessni ${ }^{c}$, M. Cherkaoui ${ }^{a}$ and A. Zarrouk ${ }^{d, *}$ \\ ${ }^{a}$ Laboratory of Materials, Electrochemistry and Environment, University Ibn Tofaïl, \\ Faculty of Science, P.O. Box 133 Kénitra, Morocco \\ ${ }^{b}$ Nemotek, Technopolis, Salé, Morocco \\ ${ }^{c}$ Laboratory of Neuroendocrinology Biotechnology and Genetics, University Ibn Tofaïl, \\ Faculty of Science, P. O. Box 133 Kénitra, Morocco \\ ${ }^{d}$ LC2AME-URAC 18, Faculty of Science, First Mohammed University, \\ P.O. Box 717, 60000 Oujda, Morocco
}

Received April 9, 2017; accepted September 4, 2017

\begin{abstract}
A new industrial electrodeposition of copper in an acidic medium using an environmental cinnamon extract has been developed. The obtained coatings were adherent and uniform, and their deposition rate has reached $23 \mu \mathrm{m} / \mathrm{h}$. In addition, their quality has been improved by cinnamon extract addition. Cyclic voltammetry and electrochemical impedance spectroscopy have showed that the electrodeposition mechanism depends on the electrolyte constituents and the additive presence. The SEM observation indicated that the coatings morphology has been improved by cinnamon extract addition.
\end{abstract}

Keywords: Copper electrodeposition, additive, cyclic voltammetry, EIS, SEM observation.

\section{Introduction}

In an industrial case herein examined, the interconnections protection process is quite rigorous. One step is the gold deposit with a thickness of 0.35 micron. In the interests of economic efficiency, it would be appealing to substitute the gold deposit by a less expensive coating. Copper electroplating is a possible solution to produce coatings with remarkable properties, at a fairly low cost [1].

Copper electronic chips technology has been developed over two decades ago [1, 2], and it has significantly improved the conductance of integrated peripherals connections. In this field, copper interconnections suffer severe degradation by the surrounding environment. Various protection methods have been used, such as metal layers deposition. Copper electroplating has been often used in

\footnotetext{
* Corresponding author. E-mail address: azarrouk@gmail.com
} 
microelectronics industry [3-6]. Copper is an excellent choice as underlayment. It has a very high plating efficiency with excellent coverage, even on substrates that are difficult to be coated.

However, copper electroplating baths usually have a quite simple formulation: copper salt and sulfuric acid. To improve the quality of the obtained deposit, several organic and inorganic additives, such as 2,2 -dipyridyle [7, 8] and $\mathrm{K}_{4} \mathrm{Fe}(\mathrm{CN})_{6}$ [9-10], were added to chemical deposition electrolytes, while thiourea [11-12], gelatin [13,14] and animal glue [15] have been added to the electrochemical deposition electrolytes. They have allowed the development of uniform and resistant copper coatings. The presence of additives in electroplating baths also produces a better leveling effect on the deposits surface [16-22]. However, their releases could present a danger to the environment. So, the search for less toxic compounds would be an alternative. Thus, the aim of this study is to formulate a new bath, using a natural additive, for developing a copper coating on interconnections used in wafer level packaging technology. The electrodeposition kinetics and mechanism have been studied using potentiostatic and electrochemical impedance spectroscopy (EIS) methods. The coating morphology has been characterized by scanning electron microscopy (SEM).

\section{Materials and methods}

The electrolysis cell was a borrosilicate glass (Pyrex $\left.{ }^{\circledR}\right)$ cylinder closed by a cap with five apertures. Three of them were used for the electrodes: copper interconnects, used in wafer level packaging technology (Fig. 1), as working electrode, Pt plate as counter electrode, while $\mathrm{Ag} / \mathrm{AgCl}$ was used as reference electrode. All potentials refer to this last electrode. All solutions used in these experiments were freshly prepared from analytical grade reagents and distilled water.

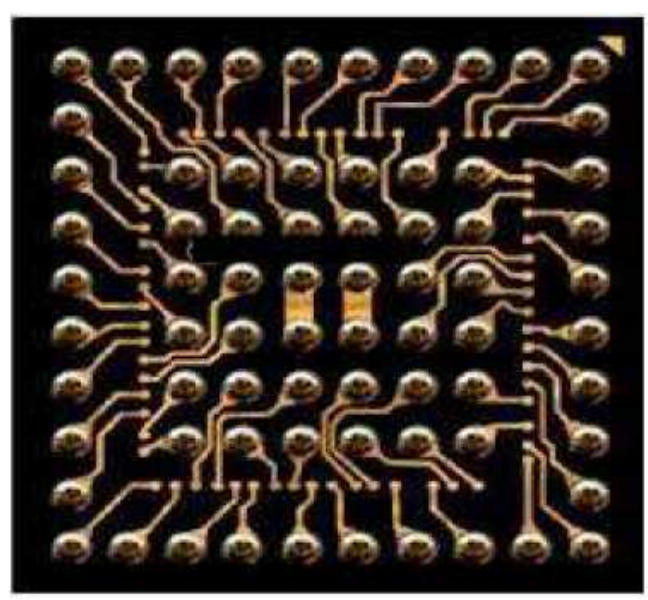

Figure 1. Interconnections used in wafer level packaging technology.

The composition and operating conditions of each plating's electrolyte are listed in Table 1 . The temperature was held at $25 \pm 2{ }^{\circ} \mathrm{C}$. The study was held in an acidic medium to meet industrial demands. 
Table 1. Electrolytes composition.

\begin{tabular}{|c|c|c|}
\hline Baths & pH & Conc. of $\mathrm{CuSO}_{4} .5 \mathrm{H}_{2} \mathrm{O}(\mathrm{g} / \mathrm{L})$ \\
\hline 1 & \multirow[t]{3}{*}{4.5} & 15 \\
\hline 2 & & 30 \\
\hline 3 & & 45 \\
\hline 4 & \multirow[t]{3}{*}{2.5} & 15 \\
\hline 5 & & 30 \\
\hline 6 & & 45 \\
\hline 7 & \multirow[t]{3}{*}{1.5} & 15 \\
\hline 8 & & 30 \\
\hline 9 & & 45 \\
\hline
\end{tabular}

Before each experiment, the substrates were degreased in ethanol, rinsed with distilled water, pickled in sulfuric acid, and then rinsed again with distilled water. The applied current densities were between $-12 \mathrm{~mA} / \mathrm{cm}^{2}$ and $-17 \mathrm{~mA} / \mathrm{cm}^{2}$. To improve the coating quality, a cinnamon extract was added to baths. The appreciation of coatings appearance has been visually performed. The deposit morphology was characterized by scanning electron microscopy (SEM) using a LEO 1530 FEG device, and the deposition rate, $\mathrm{v}_{\mathrm{d}}$, was gravimetrically determined according to the relationship:

$$
\mathrm{V}_{\mathrm{d}}=\frac{\mathrm{m}_{\mathrm{f}}-\mathrm{m}_{\mathrm{i}}}{\rho \times \mathrm{s} \times \mathrm{t}}
$$

where $m_{i}$ and $m_{f}$ are the initial and final mass $(\mathrm{g})$, respectively; $\mathrm{s}$ is the substrate surface $\left(\mathrm{cm}^{2}\right)$; $\mathrm{t}$ is the deposition time $(\mathrm{h})$ and $\rho$ is copper density $\left(\mathrm{g} / \mathrm{cm}^{3}\right)$.

The electrochemical measurements were carried out using a Potentiostat/Galvanostat/Voltalab PGZ 100, monitored by a personal computer. The cyclic voltammetry curves were recorded by polarization, with a sweep rate equal to $10 \mathrm{mV} / \mathrm{s}$. The impedance diagrams were carried out at the deposition potential.

\section{Results and discussions}

\section{Effect of $p H$}

The $\mathrm{pH}$ is an important copper electrodeposition parameter. Table 2 shows the deposition rate evolution at various $\mathrm{pH}$ values.

Table 2. Deposition rate at various $\mathrm{pH}$ values.

\begin{tabular}{|cccc|}
\hline Baths & $\mathbf{p H}$ & Conc. of $\mathbf{C u S O}_{\mathbf{4}} \mathbf{5} \mathbf{5 H}_{\mathbf{2}} \mathbf{O}(\mathbf{g} / \mathbf{L})$ & $\mathbf{v}_{\mathbf{d}}(\boldsymbol{\mu m} / \mathbf{h})$ \\
\hline 3 & 4.5 & 45 & 16.5 \\
\hline 6 & 2.5 & 45 & 17.5 \\
\hline 9 & 1.5 & 45 & 18.7 \\
\hline
\end{tabular}

It is noted that the deposition rate increases with the $\mathrm{pH}$ decrease, where a more acid $\mathrm{pH}$ causes a substrate deterioration. In addition, $\mathrm{Cu}$ precipitation is observed in the bath. According to other studies, when the $\mathrm{pH}$ becomes too high, the 
deposit becomes matt. To avoid these disadvantages, the electrolyte solutions were maintained at a constant $\mathrm{pH}$ by the addition of buffer substances. This makes possible to avoid changes in the deposit quality, which would result from changes in acidity [23]. After determining our basic bath, we have tried to improve the stability and quality of the obtained deposit, by the addition of cinnamon extract.

\section{Effect of copper concentration and current density}

Fig. 2 shows the deposition rate evolution as a function of the copper sulfate concentration at different current densities. It is remarked that the deposition rate remains substantially constant with the copper concentration in the studied range, and increases with the current density, to reach a maximum of $23 \mu \mathrm{m} / \mathrm{hat}-17$ $\mathrm{mA} / \mathrm{cm}^{2}$. In addition, at $15 \mathrm{~g} / \mathrm{L}$ and $45 \mathrm{~g} / \mathrm{L}$ of $\mathrm{CuSO}_{4} .5 \mathrm{H}_{2} \mathrm{O}$, the deposition rate increases with increasing current densities, while at $30 \mathrm{~g} / \mathrm{L}$ of $\mathrm{CuSO}_{4} .5 \mathrm{H}_{2} \mathrm{O}$, the deposition rate at $14 \mu \mathrm{A} / \mathrm{cm}^{2}$ is higher than that obtained at $15 \mu \mathrm{A} / \mathrm{cm}^{2}$.

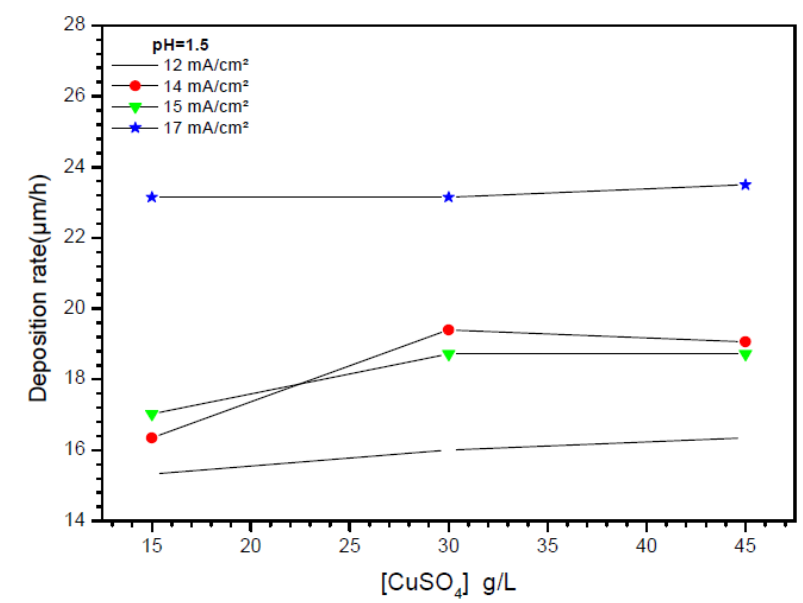

Figure 2. Copper concentration effect on deposition rate at various current densities.

Initially, the coatings aspect was visually appreciated. It is observed that the decrease in the $\mathrm{CuSO}_{4} .5 \mathrm{H}_{2} \mathrm{O}$ concentration and the increase in current deposition tend to improve the coating aspect. Thus, the optimal conditions are: $\mathrm{CuSO}_{4}$. $5 \mathrm{H}_{2} \mathrm{O} 15 \mathrm{~g} / \mathrm{L}$ at $\mathrm{pH}=1.5$ (bath 7 ), and a current density equal to $-17 \mathrm{~mA} / \mathrm{cm}^{2}$. To improve the coating quality, we have added an additive, cinnamon extract, to the electrolyte. This additive is natural and non-toxic to the environment.

\section{Effect of cinnamon concentration on the deposition rate GC-MS analysis of cinnamon extract}

The essential oils have been analyzed by gas chromatography coupled to mass spectrometry (GC-MS), using the Thermo Fisher apparatus in UATRS - cnrst, Rabat, Morocco. The cinnamon essential oil constituents are presented in Table 3. From the cinnamon essential oil chromatographic analysis by GC/MS, we have found that 38 compounds represent $86.21 \%$ of this oil, with transcinnamaldehyde $(46.30 \%), \delta$-cadinene $(8.16 \%)$ and $\beta$-cubebene $(5.20 \%)$ being the major constituents. 
Table 3. Composition of cinnamon essential oils extraction.

\begin{tabular}{|c|c|c|}
\hline Retention time (min) & Compounds & Indicative value \% \\
\hline 3.01 & $\alpha$-phellandrene & 0.01 \\
\hline 3.06 & D 3-carene & 0.02 \\
\hline 3.10 & $\alpha$-terpinene & 0.01 \\
\hline 3.16 & p-cymene & 0.21 \\
\hline 3.20 & limonene & 0.17 \\
\hline 3.23 & 1,8-cineole & 0.13 \\
\hline 3.29 & phenylacetaldehyde & 0.02 \\
\hline 3.42 & $\gamma$-terpinene & 0.05 \\
\hline 3.47 & acetophenone & 0.09 \\
\hline 3.65 & terpinolene & 0.07 \\
\hline 3.71 & trans $\beta$-ocimene & 0.04 \\
\hline 3.80 & $\alpha$-thujone & 0.11 \\
\hline 3.88 & $\beta$-thujone & 0.23 \\
\hline 4.00 & benzene terbutyl & 0.28 \\
\hline 4.10 & 2-methyl benzofuran & 0.02 \\
\hline 4.12 & camphor & 0.28 \\
\hline 4.23 & hydrocinnamaldehyde & 1.64 \\
\hline 4.28 & borneol & 0.42 \\
\hline 4.36 & terpinen-4-ol & 0.07 \\
\hline 4.46 & $\alpha$-terpinol & 0.20 \\
\hline 4.50 & estragole & $\operatorname{Tr}$ \\
\hline 4.69 & cis cinnamaldehyde & 1.62 \\
\hline 4.86 & cuminicaldehyde & 1.27 \\
\hline 5.28 & transcinnamaldehyde & 46.30 \\
\hline 5.72 & eugenole & 0.12 \\
\hline 5.82 & $\alpha$-copaene & 1.36 \\
\hline 5.89 & $\beta$-cubebene & 5.20 \\
\hline 5.96 & $\beta$-selinene & 0.43 \\
\hline 5.98 & valancene & 0.38 \\
\hline 6.02 & viridiflorene & 0.62 \\
\hline 6.23 & $\alpha$-logipinene & 0.29 \\
\hline 6.52 & $\alpha$-murolene & 3.97 \\
\hline 6.68 & $\gamma$-cadinene & 4.84 \\
\hline 6.83 & $\delta$-cadinene & 8.16 \\
\hline 7.48 & cubenol & 1.69 \\
\hline 7.57 & T-cadinol & 4.58 \\
\hline 7.75 & cadalene & 1.21 \\
\hline 8.22 & benzyl benzoate & 0.10 \\
\hline \multicolumn{2}{|l|}{ Total } & 86.21 \\
\hline
\end{tabular}

Fig. 3 shows cinnamon's influence on the deposition rate at different concentrations. It is seen that cinnamon extract addition slightly decreases the deposition rate from $23 \mu \mathrm{m} / \mathrm{h}$ to $20 \mu \mathrm{m} / \mathrm{h}$. Furthermore, it is observed a significant improvement in the quality of the obtained coating, with a higher cinnamon concentration, where the best appearance was obtained at $100 \mathrm{ppm}$.

\section{Scanning electronic microscopy morphology}

The morphology of electrodeposited copper interconnections obtained from electrolyte 7, with and without additive, was characterized by SEM. It is noted 
that the deposits obtained from electrolyte 7, without additive, present some pores and irregularities (Fig. 4a). By contrast, the deposit obtained in the presence of $100 \mathrm{ppm}$ of cinnamon was more regular, no porous and smooth (Fig. 4b).

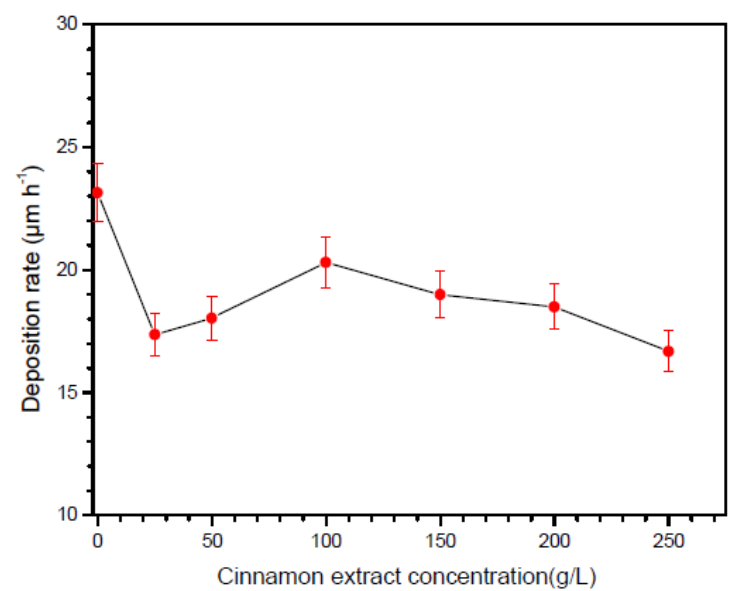

Figure 3. Effect of cinnamon extract concentration on the deposition rate in electrolyte (7) at $\mathrm{I}=-17 \mathrm{~mA} / \mathrm{cm}^{2}$.
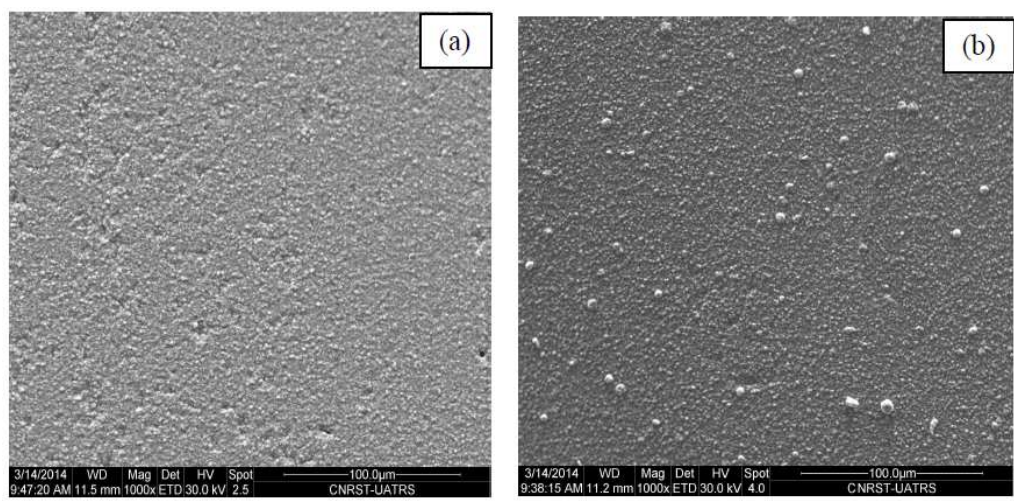

Figure 4. SEM micrographs of copper deposit obtained from electrolyte (7) at $\mathrm{I}=-17$ $\mathrm{mA} / \mathrm{cm}^{2}$ (a) without additive and (b) with $100 \mathrm{ppm}$ of cinnamon extract.

A larger view of the interconnection shows that the coating formed from the electrolyte (7), in the additive presence, is truly uniform over the whole surface (Fig. 5).

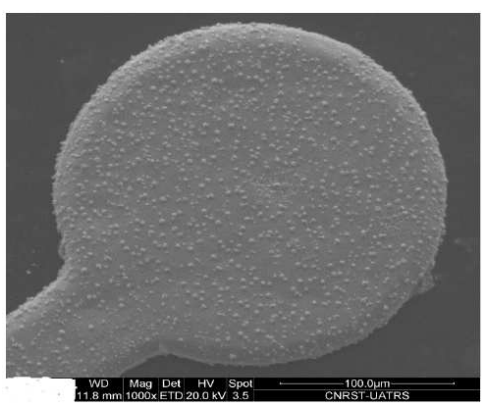

Figure 5. SEM micrographs of an interconnection covered by a copper deposit. 


\section{Deposition mechanism}

\section{Chronopotentiometry}

Fig. 6 shows the chronopotentiograms, with and without the addition of cinnamon extract. It is found that the copper electrodeposition potential, obtained from electrolyte (7), in the absence of additive, is equal to $-0.20 \mathrm{~V} / \mathrm{Ag} / \mathrm{AgCl}$, which has cathodically decreased with additive, to reach a minimum at $250 \mathrm{ppm}$ $(-0.3 \mathrm{~V} / \mathrm{Ag} / \mathrm{AgCl})$ of cinnamon extract. This result can be explained by the change in the electrode surface, leading to the the variation in the deposition rate.

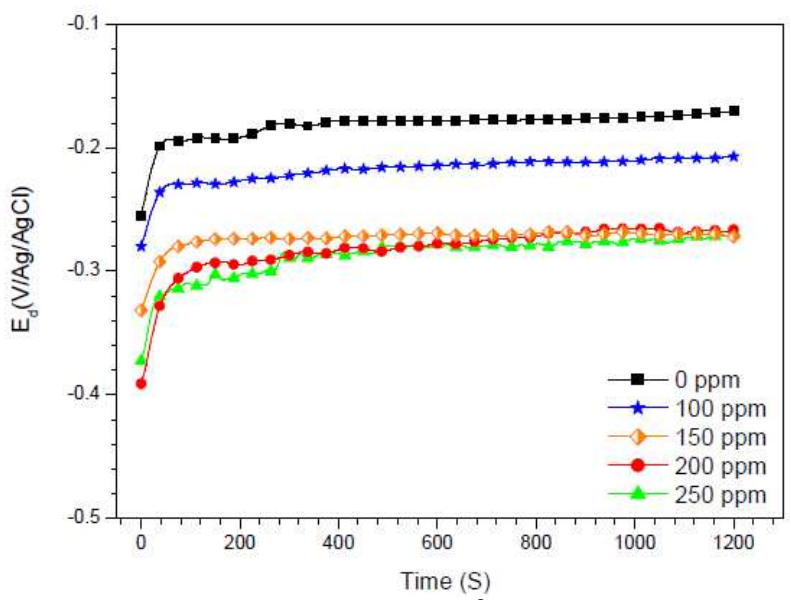

Figure 6. Chronopotentiograms at $-17 \mathrm{~mA} \mathrm{~cm}$, without and with different cinnamon extract concentrations.

\section{Cathodic curves study}

Fig. 7 shows the cathodic curves obtained in baths containing $\mathrm{H}_{2} \mathrm{SO}_{4}$, with and without $100 \mathrm{ppm}$ of cinnamon extract and/or copper sulfate. It is noted that the hydrogen reduction starts from $-0.8 \mathrm{~V} / \mathrm{Ag} / \mathrm{AgCl}$ in the solution containing only $\mathrm{H}_{2} \mathrm{SO}_{4}$ (while after addition of cinnamon extract, this potential shifts to 1.1 $\mathrm{V} / \mathrm{Ag} / \mathrm{AgCl}$ ), and that no plate was observed. This result indicates that the organic additive was not of an electroactive species. It can be seen a significant decrease in the cathodic current density, in the presence of the additive, which can be attributed to a drop in the $\mathrm{H}^{+}$ions discharge. This could explain the decrease in pitting on coatings made from baths containing the additive.

So, in the presence of $\mathrm{CuSO}_{4}$ with $\mathrm{H}_{2} \mathrm{SO}_{4}$, it is seen a region with different current/potential functionalities, as expected of a change in the process kinetics at different potentials. Thus, the polarization curve showed that, from -0.040 $\mathrm{V} / \mathrm{Ag} / \mathrm{AgCl}$ up to $-0.40 \mathrm{~V} / \mathrm{Ag} / \mathrm{AgCl}$, the cathodic process is under activation control, whereas from $-0.40 \mathrm{~V} / \mathrm{Ag} / \mathrm{AgCl}$ to $-0.80 \mathrm{~V} / \mathrm{Ag} / \mathrm{AgCl}$, it was mass transport-controlled; and from $\mathrm{E}=-0.8 \mathrm{~V} / \mathrm{Ag} / \mathrm{AgCl}$, it became an hydrogen evolution [22, 24-26]. In addition, the pale diffusion was attributed to $\mathrm{Cu}^{2+}$ reduction, such as mentioned by Anik et al. [6]. However, in the cinnamon extract addition to the electrolyte (7), the hydrogen reduction potential was shifted to more negative values, with a remarkable decrease in the cathodic current density. It is noted that copper current diffusion was decreased by the additive, indicating a decrease in the deposition rate. This can be interpreted as a surface blockage, confirming chronopotentiometry results. The gravimetrically 
recorded increase in the deposition rate, between $-12 \mathrm{~mA} / \mathrm{cm}^{2}$ and $-17 \mathrm{~mA} / \mathrm{cm}^{2}$, was also confirmed. Indeed, in this current zone, the deposition process is activation-controlled. It is noted that the current density required to obtain a good quality deposit $\left(-17 \mathrm{~mA} / \mathrm{cm}^{2}\right)$ is much lower than the diffusion current limit, which is around $-30 \mathrm{~mA} / \mathrm{cm}^{2}$.

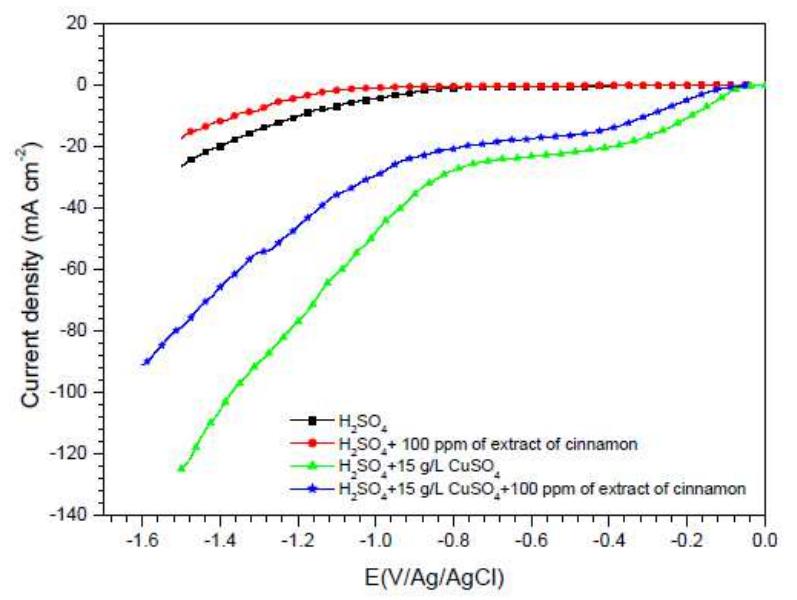

Figure 7. Cathodic curves for baths containing $\mathrm{H}_{2} \mathrm{SO}_{4}$, with and without $100 \mathrm{ppm}$ of cinnamon extract and/or copper sulfate $(\mathrm{V}=10 \mathrm{mV} / \mathrm{s})$.

\section{Cyclic voltammetry study}

Fig. 8 shows the voltammogramms obtained from electrolyte (7), without and with $100 \mathrm{ppm}$ of cinnamon extract. The shape of the voltammogramms remained similar with and without additive. The first cathodic peak at $-0.037 \mathrm{~V} / \mathrm{Ag} / \mathrm{AgCl}$ (peak B) was attributed to the copper reduction, followed by hydrogen evolution at $-0.8 \mathrm{~V} / \mathrm{Ag} / \mathrm{AgCl}$ (peak $\mathrm{C}$ ) [6]. In the anodic range, it is observed a peak (A) at $0.39 \mathrm{~V} / \mathrm{Ag} / \mathrm{AgCl}$, associated to copper dissolution formed during cathodic scan. In presence of the cinnamon extract, a displacement of the peak $\mathrm{C}$ to the cathodic direction, and a decrease in its current intensity, were observed. It was also noted a small decrease in the peak $\mathrm{B}$, indicating a decrease in the deposition rate. This is in agreement with previous results, which showed that cinnamon extract acts on the cathodic process by hydrogen inhibition and copper reduction.

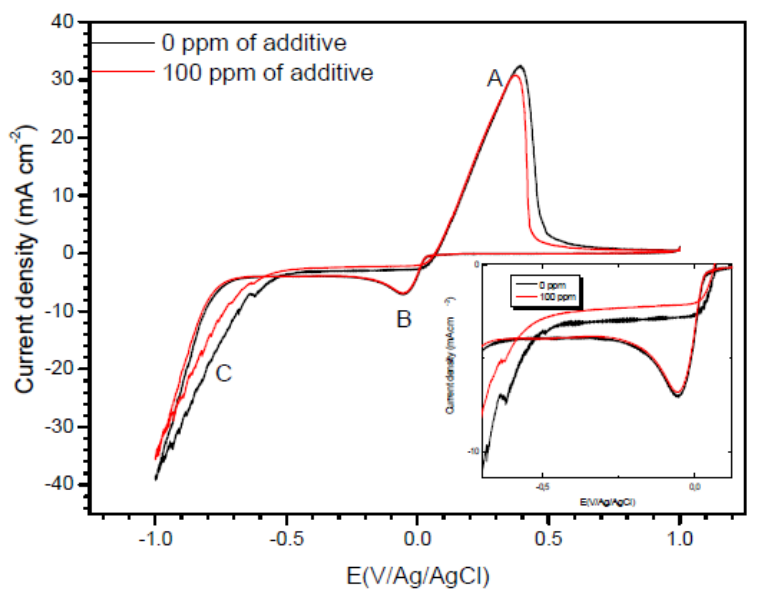

Figure 8. Cyclic voltammograms from electrolyte 7, without and with $100 \mathrm{ppm}$ of cinnamon extract $(\mathrm{V}=10 \mathrm{mV} / \mathrm{s})$. 


\section{Electrochemical impedance study}

The Nyquist impedance spectra of copper electrodeposition, without and with 100 ppm of cinnamon extract, are presented in Figs. 9 and 10. The impedance diagram plots done without cinnamon extract reveal (Fig. 9):

- a first loop at high frequency, attributed to the relaxation of the double layer capacitance around $20 \mu \mathrm{Fcm}^{-2}$, in parallel with the charge transfer resistance, $\mathrm{R}_{\mathrm{t}}$, inversely proportional to the deposition rate;

- a capacitive loop at the intermediate frequency. This can be attributed to copper discharge, which is controlled by mass transport [27]. The linear portion slope is equal to 0.9 ; this value close to 1 is characteristic of a diffusion phenomenon that takes place in a solution [28]. The difference between the theoretical value and the obtained one may be justified by the low deconvolution between the first and the second loop, i.e. the end of the first loop influences the beginning of the second;

- and an inductive loop at low frequency, often attributed to electrocrystallization [29].

However, in the additive's presence, two loops were observed. The first loop at the high frequencies was attributed to the response of charge transfer resistance, of which capacitance value is equal to $3.3 \mu \mathrm{Fcm}^{-2}$, much lower than that obtained without the additive. The second loop at the intermediate frequencies was attributed to the copper ions discharge (Fig. 10). In addition, the linear portion is also noticed in the beginning of the last loop (the bath without additive); the slope is significantly lower, where its value is approximately equal to 0.5 . These observations are not characteristic of a diffusion phenomenon in the solution, but may result from diffusion through a thin layer formed at surface by additive adsorption. The additive effect can be further demonstrated by the maximum frequency of the second loop. It is, indeed, very different without and with additive.

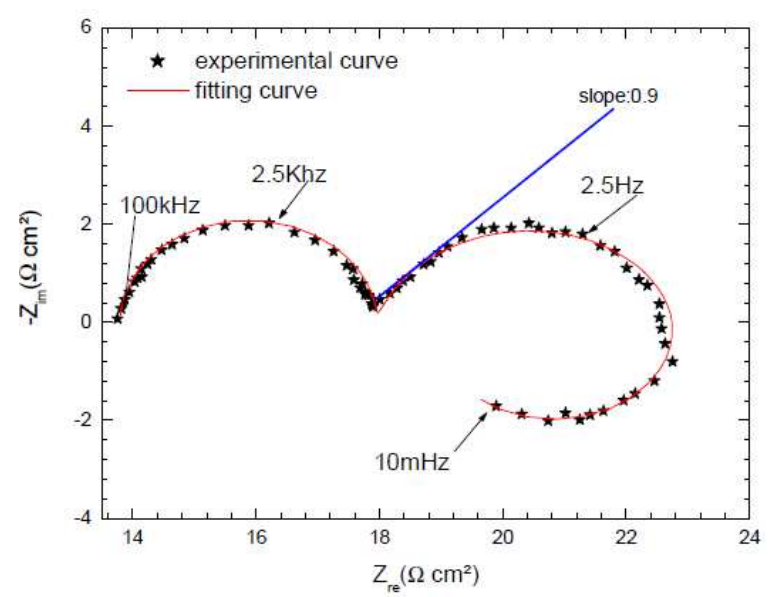

Figure 9. Electrochemical impedance spectra at deposition potentials without additive. Symbols: experimental data. Red continuous lines: fitting data. 


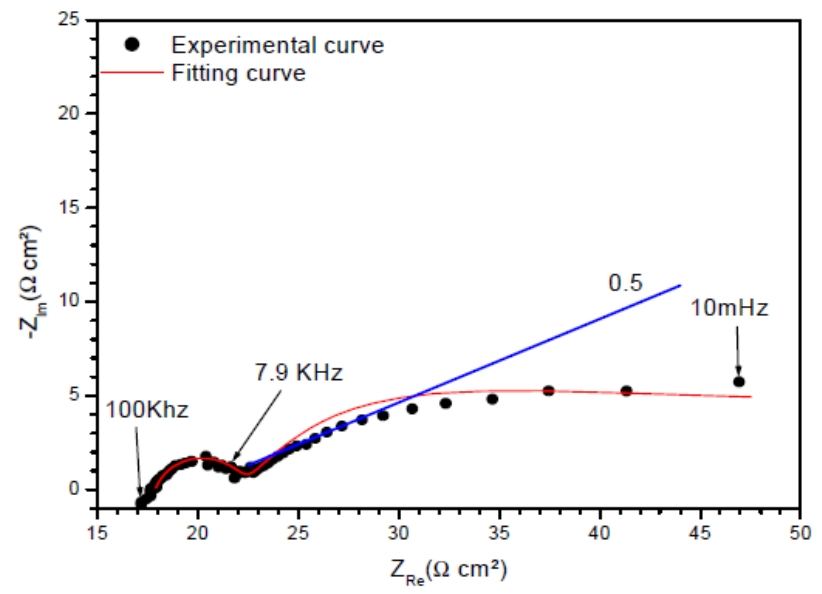

Figure 10. Electrochemical impedance spectra at deposition potentials with $100 \mathrm{ppm}$ of additive. Symbols: experimental data. Red continuous lines: fitting data.

For modeling the impedance diagrams, it has been taken into account that the resulting loops are flattened semicircles. The deviations from a perfect circular form are often related to the frequency dispersion of interfacial impedance, arising from a lack of electrode homogeneity surface, due to roughness or interfacial phenomena [29]. The EIS results without additive were simulated using the equivalent circuit shown in Fig. 11a, while that in the presence of additive was shown in Fig. 11b, in relation to pure electric models. These can verify or rule out mechanistic models, and enable the calculation of numerical values corresponding to the physical and/or chemical properties of the electrochemical system under investigation. The employed circuit allowed for the identification of the solution resistance $\left(R_{e}\right)$, charge transfer resistance $\left(R_{t}\right)$ and discharge resistance associated with the formed layer of products $\left(R_{f}\right)$. It is worthy to note that the double layer capacitance $\left(\mathrm{C}_{\mathrm{f}}\right)$ value was affected by surface imperfections, and this effect was simulated via a constant phase element $\mathrm{CPE}\left(\mathrm{Q}_{\mathrm{f}}, \mathrm{n}\right)$ [30]. The employment of $\mathrm{Q}_{\mathrm{f}}$ and $\mathrm{n}$ parameters is justified when their changes are related to the surface heterogeneity resulting from surface roughness, adsorption and porous layer formation. Indeed, Fig. 4 has showed that the coatings presented some roughness. So, the depressed feature was represented by the following expression, close to the frequency distribution of the dielectric behavior called Cole-Cole type dispersion of time constant [31]:

$$
\mathrm{Z}=\frac{\mathrm{R}}{1+(\mathrm{j} \omega \mathrm{RC})^{\alpha}}
$$

This expression differs from the constant phase element (CPE) impedance, frequently used nowadays, where $\mathrm{CPE}$ and $\mathrm{R}$ impedance of parallel connection will be expressed as [32]:

$$
\mathrm{Z}=\frac{\mathrm{R}}{1+\mathrm{R} \times \mathrm{CPE}(\mathrm{j} \omega)^{\alpha}}
$$

The simulated impedance parameters are shown in Table 4. It is observed a good correlation between experimental and simulated data. According to these results, $R_{t}$, transfer resistance, was slightly increased from $4.15 \Omega \mathrm{cm}^{2}$ to $5.5 \Omega \mathrm{cm}^{2}$, with 
$100 \mathrm{ppm}$ of additive, confirming a low impact on the deposition rate. It is also noted that $\mathrm{R}_{\mathrm{f}}$ value, the resistance of the ionic transfer through the film, in the additive's presence, is higher than that in its absence.

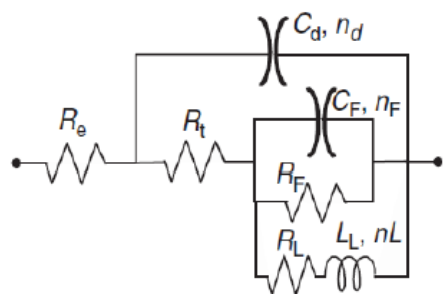

(a)

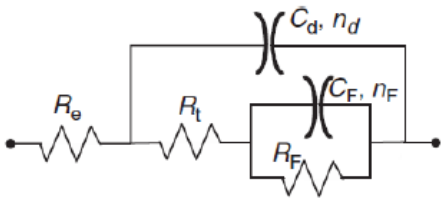

(b)

Figure 11. Equivalent circuit models used to fit the experiment impedance data (a) without additive and (b) with 100 ppm of additive.

\section{Conclusion}

In this study, we have developed a copper coating on interconnections used in wafer level packaging technology. We have found that copper electrodeposition rate and deposit quality depend on the sulfate copper concentration, $\mathrm{pH}$ and current densities. In order to improve the deposition quality, a cinnamon extract additive was used. It was found that the coating quality was improved; less porosity and greater regularity were observed by scanning electron microscopy, without decreasing the deposition rate.

Table 4. Electrochemical parameters data obtained from electrolyte (7), without and with $100 \mathrm{ppm}$ of additive.

\begin{tabular}{|c|c|c|c|c|c|c|c|c|c|}
\hline \multicolumn{5}{|c|}{ CPE1 } & \multicolumn{5}{|l|}{ CPE2 } \\
\hline Conc & $\begin{array}{c}\mathbf{R}_{\mathbf{e}} \\
\left(\mathbf{\Omega c m}^{2}\right)\end{array}$ & $\begin{array}{c}\mathrm{C}_{\mathrm{d}} \\
\left(\mu \mathrm{Fcm}^{-2}\right)\end{array}$ & $\mathbf{n}_{\mathrm{dl}}$ & $\begin{array}{c}\mathbf{R}_{\mathrm{t}} \\
\left(\mathbf{\Omega c m}^{2}\right)\end{array}$ & $\begin{array}{c}\mathrm{C}_{\mathrm{F}} \\
\mathrm{mFcm}^{-2}\end{array}$ & $\overline{n_{F}}$ & $\begin{array}{c}\mathbf{R}_{\mathbf{F}} \\
\left(\mathbf{g}^{2}\right)\end{array}$ & $\begin{array}{c}\mathbf{L} \\
(\mathbf{H})\end{array}$ & $\begin{array}{c}\mathbf{R}_{\mathrm{L}} \\
\left(\mathbf{\Omega c m}^{2}\right)\end{array}$ \\
\hline 00 & 13.9 & 90 & 0.68 & 4.15 & 20 & 0.81 & 4.34 & 148 & 0.5 \\
\hline 100 & 13.6 & 3.3 & 0.62 & 5.5 & 212 & 0.84 & 50 & - & - \\
\hline
\end{tabular}

In addition, investigations by stationary polarization, cyclic voltammetry and electrochemical impedance showed that the additive has influenced the electrodeposition mechanism. So, the hydrogen reduction potential was shifted to more cathodic values, and the impedance diagrams showed a change in the copper deposit mechanism. Thus, without additive, a diffusional process occurs in the solution, while in its presence, the diffusion would occur through a thin layer formed on the surface. However, SEM observations have indicated that the deposit quality has improved with additive, by its adsorption on the electrode surface.

\section{Acknowledgments}

The authors are thankful to Nemotek Technology, for the financial assistance. 


\section{References}

1. Andricacos PC, Uzoh C, Dukovik JO, et al. Damascene copper electroplating for chip interconnections. IBM J Research Development. 1998;42: 567-574.

2. Andricacos PC. Interface, Electroplated Copper Writing on IC Chips. Interface 1998;7:23.

3. Topper M, Stolle T, Reichl H. Low cost electroless copper metallization of BCB for high-density wiring systems. Proceedings of International Symposium on AD. IEEE Int Microelectr and Packaging Soc; 1999. pp 202208.

4. Sullivan OEJ. In: Romankiw LT, Osaka T, Yamasaki Y, et al, editors. Electrochemical technology. Electrochem Soc Japan; 2000. p. 159.

5. Plieth W. Additives in the electrocrystallization process. Electrochim Acta. 1992;37:2115-2121.

6. Anik $\mathrm{T}$, El Haloui A, Touhami ME, et al. Influence of $\mathrm{N}-\mathrm{N}$ dimethyl formamide on electroless copper plating using hypophosphite as reducing agent. Surf Coat Technol. 2014;245:22-27.

7. Li J, Hayden H, Kohl PA. The influence of 2,2'-dipyridyl on nonformaldehyde electroless copper plating. Electrochim Acta. 2004;49:17891795.

8. Kou SC, Hung A. Plat Surf Finish. 2003;90:44.

9. Gan X, Wu Y, Liu L, et al. Effects of $\mathrm{K}_{4} \mathrm{Fe}(\mathrm{CN})_{6}$ on electroless copper plating using hypophosphite as reducing agent. J Appl Electrochem. 2007;37:899-904.

10. Gan X, Wu Y, Liu L, et al. Electroless copper plating on PET fabrics using hypophosphite as reducing agent. Surf Coat Technol. 2007;201:7018-7023.

11. Suarez DF, Olson FA. Nodulation of electrodeposited copper in the presence of thiourea. J Appl Electrochem. 1992;22:1002-1010.

12. Alodan MA, Smyrl WH. Confocal Laser Scanning Microscopy, Electrochemistry, and Quartz Crystal Microbalance Studies of Leveling Effects of Thiourea on Copper Deposition. J Electrochem Soc. 1998; 145:957-963.

13. Cofré P, Bustos A. Voltammetric behaviour of the copper(II)-thiourea system in sulphuric acid medium at platinum and glassy carbon electrodes. $\mathrm{J}$ Appl Electrochem. 1994;24:564-568.

14. Fabricius G, Kontturi K, Sundholm G. Influence of thiourea and thiourea ageing on the electrodeposition of copper from acid sulfate solutions studied by the ring-disc technique. J Appl Electrochem. 1996;26:1179-1183.

15. Muresan L, Varvara S, Maurin G, et al. The effect of some organic additives upon copper electrowinning from sulphate electrolytes. Hydrometallurgy. 2000;54:161-169.

16. Varvara S, Muresan L, Popescu IC, et al. Kinetics of copper electrodeposition in the presence of triethyl-benzyl ammonium chloride. J Appl Electrochem. 2003;33:685-692.

17. Moffat TP, Bonevich JE, Huber W, et al. Superconformal Electrodeposition of Copper in 500-90 nm Features. J Electrochem Soc. 2000;147:4524-4535. 
18. West AC, Mayer S, Reid J. A Superfilling Model that Predicts Bump Formation. Electrochem Solid-State Lett. 2001;4:C50-C53.

19. Flott LW. Electrostatic spray guns: ITW Ransburg Electrostatic Systems Toledo, Ohio. Metal Finish. 1996; 94: 55-56.

20. Passal F. Copper Plating during the last Fifty Years. Plating. 1959;46:628638.

21. Hosseini M, Ebahimi S. The effect of $\mathrm{Tl}(\mathrm{I})$ on the hard gold alloy electrodeposition of $\mathrm{Au}-\mathrm{Co}$ from acid baths. J Electroanaly Chem. 2010;645:109-114.

22. Pasquale MA, Gassa LM, Ariva AJ. Copper electrodeposition from an acidic plating bath containing accelerating and inhibiting organic additives. Electrochim Acta. 2008;53:5891-5904.

23. D. Landolt. Corrosion et chimie de surface des métaux traité de matériaux. Polytechnique et universitaire Romandes: Paris; 1993. p. 488-499.

24. Mattson E, Bockris JOM. Galvanostatic studies of the kinetics of deposition and dissolution in the copper + copper sulphate system Trans Faraday Soc. 1959;55:1586-1601.

25. Losev VV, Skribnyi LE, Molodov AI. Stage occurrence of electrode processes on copper amalgam. Elektrokhimiya. 1966;2:1431-1437.

26. Stoychev D, Tsvetanov C. Behaviour of poly(ethylene glycol) during electrodeposition of bright copper coatings in sulfuric acid electrolytes. J Appl Electrochem. 1996;26:741-749.

27. Ohno I, Wakabayashi O, Haruyama S. Anodic Oxidation of Reductants in Electroless Plating. J Electrochem Soc. 1985;132:2323-2330.

28. Diard JP, Gorrec B, Montella C. Cinétique électrochimique. Edition Hermann; 1996.

29. Bouyanzer A, Hammouti B, Majidi L. Pennyroyal oil from Mentha pulegium as corrosion inhibitor for steel in $1 \mathrm{M} \mathrm{HCl}$. Mater Lett. 2006;60:2840-2843.

30. Benabdellah M, Souane R, Cheriaa N, Abidi R, Hammouti B, Vicens J., Synthesis of calixarene derivatives and their anticorrosive effect on steel in 1M HCl, Pigment Resin Technol. 2007;36:373-381.

31. Cole KS, Cole RH. Dispersion and Absorption in Dielectrics I. Alternating Current Characteristics. J Chem Phys. 1941;9:341-351.

32. Marušić K, Ćurković HO, Takenouti H. Inhibiting effect of 4-methyl-1-ptolylimidazole to the corrosion of bronze patinated in sulphate medium. Electrochim Acta 2011;56: 7491-7502. 